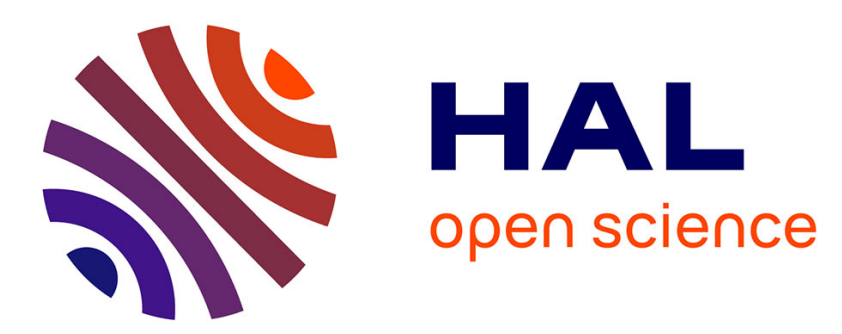

\title{
Vision-based control of a flying Spherical Inverted Pendulum on a Quadrotor
}

Soukaina Krafes, Zakaria Chalh, Abdelmjid Saka

\section{To cite this version:}

Soukaina Krafes, Zakaria Chalh, Abdelmjid Saka. Vision-based control of a flying Spherical Inverted Pendulum on a Quadrotor. International Meeting on Advanced Technologies in Energy and Electrical Engineering, Nov 2018, Fez, Morocco. hal-01941607

\section{HAL Id: hal-01941607 https://hal.science/hal-01941607}

Submitted on 1 Dec 2018

HAL is a multi-disciplinary open access archive for the deposit and dissemination of scientific research documents, whether they are published or not. The documents may come from teaching and research institutions in France or abroad, or from public or private research centers.
L'archive ouverte pluridisciplinaire HAL, est destinée au dépôt et à la diffusion de documents scientifiques de niveau recherche, publiés ou non, émanant des établissements d'enseignement et de recherche français ou étrangers, des laboratoires publics ou privés. 
Vision-based control of a flying Spherical Inverted Pendulum on a Quadrotor

*Soukaina Krafes

${ }^{1, *}$ Soukaina Krafes, ${ }^{1, * *}$ Zakaria Chalh, ${ }^{1, * * *}$ Abdelmjid Saka

${ }^{1}$ Ingénierie, Systèmes et Applications Laboratory

National School of Applied Sciences, Sidi Mohamed Ben Abdellah University, Fez, Morocco

* soukaina.krafes@usmba.ac.ma, ${ }^{* *}$ zakaria.chalh@usmba.ac.ma,

abdelmjid.saka@usmba.ac.ma

A spherical inverted pendulum represents an example of a nonlinear and unstable dynamical system. It has the property of the impossibility of measurement at the ball joint. It must be noted here the absence of sensors that can measure states at the ball joints. The spherical inverted pendulum is also called an under-actuated system because it has a greater number of joints than the number of actuators. The control of under-actuated systems is currently a field of research that is very active due to their vast applications in robotics, aerospace and marine vehicles. Furthermore, the interest of the scientific community to the theme of controlling the spherical Inverted Pendulum has continued to increase, especially because it is more reasonable to model many applications of the inverted pendulum, like the Segway [1] that can lean to the left or right or a humanoid robot [2] as a spherical inverted pendulum than a simple one. Most of researchers have developed control strategies to control the spherical inverted pendulum by applying two planar forces $f_{x}$ and $f_{y}$ along the $\mathrm{x}$-axis and $y$-axis respectively. However, they were all discussed in terms of decoupled techniques which means that they have considered the Spherical Inverted Pendulum as two simple inverted pendulums which has made the region of stability limited [3], [4] and [5]. From an application point of view, such limitations will be removed by enlarging the region of stability by adding a vertical force $f_{z}$ along the $\mathrm{z}$-axis. In this way, the base will become capable of moving in the space in order to control the pendulum.

In order to achieve this goal, this paper proposes an inverted pendulum that is attached by a ball joint to a Quadrotor such that this last enables to control the Spherical Inverted Pendulum in its unstable equilibrium upright position. The thing that has already attracted many attentions [6-12]. However, most of these research were discussed either in terms of decoupling or they considered a simple inverted pendulum with different initial conditions of the angle and angular velocity of the pendulum. In other terms, in order to control an inverted pendulum in real life, the angular positions and angular speeds must be measured using an 
IMAT3E' 18

International Meeting on Advanced Technologies in Energy and Electrical

Engineering

IMAT3E

encoder at the bearing. The thing that is impossible for the case of the spherical inverted pendulum.

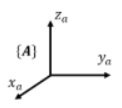

Figure 1. The Flying Spherical Inverted Pendulum
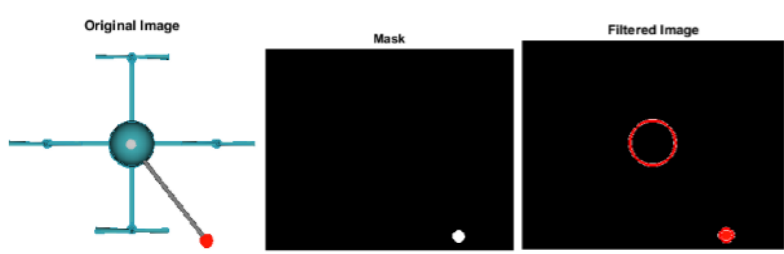

Figure 2. Resulting images after applying the algorithm.

In this paper, the visual servoing of a Spherical Inverted Pendulum on a Quadrotor Fig. 1 is treated. This technique will control the spherical pendulum in the vertical position based on visual information from a camera placed over the Quadrotor. The camera records images from the environment and on the basis of certain characteristic points of the observed image, the current position of the pendulum will, therefore, be derived from the desired position Fig.2. This difference in image characteristics between the current location and the desired location is then used to generate a backstepping-based control which will cause the Quadrotor to move in order to adjust the position of the spherical pendulum in its equilibrium position unstable Fig. 3, 4, 5 and 6.

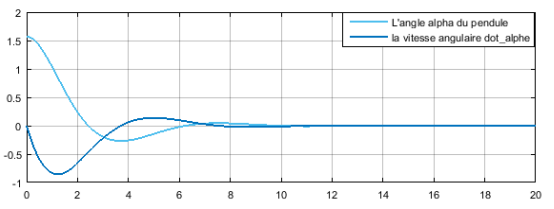

Figure 3. Simulation result for the angle $\alpha$ and its velocity of the Spherical Inverted Pendulum

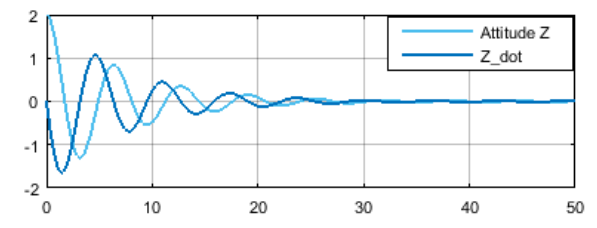

Figure 4. Simulation result for the altitude $\mathrm{z}$ of the Quadrotor
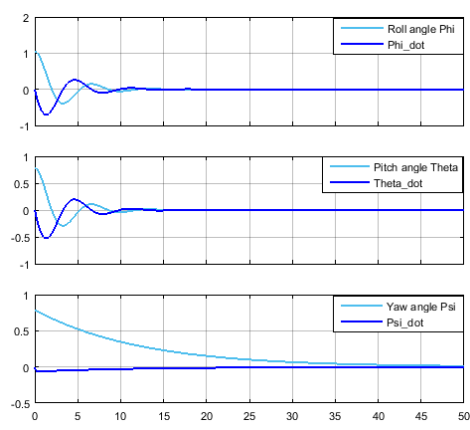

Figure 5. Simulation result for the rotational movement of the Quadrotor
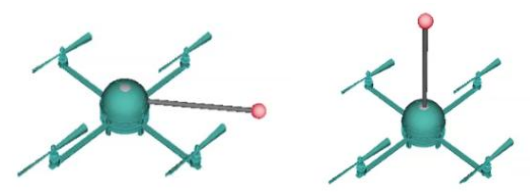

Figure 6. Screenshot of the virtual reality environment of the system in Simulink. 
IMAT3E' 18

International Meeting on Advanced Technologies in Energy and Electrical

Engineering

\section{References}

1. A. Castro, C. Adams and W. Singhose, "Dynamic response characteristics of a two-wheeled invertedpendulum transporter," 52nd IEEE Conference on Decision and Control, Firenze, 2013, pp. 1532-1537. doi: 10.1109/CDC.2013.6760100

2. J. Jovic, V. Bonnet, C. Fattal, P. Fraisse, Ch. Azevedo Coste, A new 3D center of mass control approach for FES-assisted standing: First experimental evaluation with a humanoid robot, Medical Engineering \& Physics, Volume 38, Issue 11, 2016, Pages 1270-1278, http://dx.doi.org/10.1016/j.medengphy.2016.09.002.

3. S. T. Kao, W. J. Chiou, and M. T. Ho, "Balancing of a spherical inverted pendulum with an omni-directional mobile robot," 2013 IEEE International Conference on Control Applications (CCA), Hyderabad, 2013, pp. 760-765. doi: 10.1109/CCA.2013.6662841

4. C. C. Tsai, C. C. Yu, and C. S. Chang, "Aggregated hierarchical sliding-mode control for spherical inverted pendulum," 2011 8th Asian Control Conference (ASCC), Kaohsiung, 2011, pp. 914-919

5. A. Ghanbari and M. Farrokhi, "Decentralized Neuro-Fuzzy Controller Design Using Decoupled SlidingMode Structure for Two-Dimensional Inverted Pendulum," 2006 IEEE International Conference on Engineering of Intelligent Systems, Islamabad, 2006, pp. 1-6. doi: 10.1109/ICEIS.2006.1703155

6. M. Hehn and R. D'Andrea, "A flying inverted pendulum," 2011 IEEE International Conference on Robotics and Automation, Shanghai, 2011, pp. 763-770. doi: 10.1109/ICRA.2011.5980244

7. F. Cai, T. Lai, Q. Chai and W. Wang, "Trajectory tracking problem of a quad-rotor Pendulum," 2016 Chinese Control and Decision Conference (CCDC), Yinchuan, 2016, pp. 578-582. doi: 10.1109/CCDC.2016.7531052

8. C. Raimúndez, J. L. Camaño, and A. Barreiro, "Stabilizing an inverted spherical pendulum using a scale quad-rotor," The 4th Annual IEEE International Conference on Cyber Technology in Automation, Control and Intelligent, Hong Kong, 2014, pp. 111-116. doi: 10.1109/CYBER.2014.6917445

9. A. M. Bloch, N. E. Leonard, and J. E. Marsden, "Controlled Lagrangians and the stabilization of mechanical systems. I. The first matching theorem," in IEEE Transactions on Automatic Control, vol. 45, no. 12, pp. 2253-2270, Dec 2000. doi: 10.1109/9.895562

10. T. Ibuki, Y. Tadokoro, Y. Fujita and M. Sampei, "3D inverted pendulum stabilization on a quadrotor via bilinear system approximations," 2015 IEEE Conference on Control Applications (CCA), Sydney, NSW, 2015, pp. 513-518. doi: 10.1109/CCA.2015.7320681

11. Y. Fujita, T. Ibuki, and M. Sampei, "Bilinear system approximation-based inverted pendulum stabilization in three dimensions," 2014 Proceedings of the SICE Annual Conference (SICE), Sapporo, 2014, pp. 10231028. doi: 10.1109/SICE.2014.6935246

12. Zhang, C., Hu, H., Gu, D., \& Wang, J. (2017). Cascaded control for balancing an inverted pendulum on a flying quadrotor. Robotica, 35(6), 1263-1279. doi:10.1017/S0263574716000035 